I Fundação Oswaldo Cruz (Fiocruz), Casa de Oswaldo Cruz (COC),

Rio de Janeiro, RJ, Brasil

andrevbitt@gmail.com

https://orcid.org/oooo-o0oI-52 I I-0250

Andre Bittencourt '

\title{
PERSONALIDADE E DESTINO: PEDRO NAVA, MÁRIO DE ANDRADE E A SOCIALIZAÇÃO DO MODERNISMO
}

\author{
A correspondência é a forma utópica \\ da conversa porque anula o presente e faz do \\ futuro o único lugar possível do diálogo. \\ (Ricardo Piglia, Respiração artificial)
}

\section{INTRODUÇÃO}

A relação de Mário de Andrade com os escritores mineiros se inicia em abril de I924, na famosa Caravana Modernista, que levou Mário, Oswald de Andrade, Tarsila do Amaral, Blaise Cendrars, entre outros, às hoje chamadas cidades históricas. Retornando dessa imersão em igrejas, esculturas e casarios barrocos o grupo fica alguns dias em Belo Horizonte, a nova capital do estado, fundada há menos de três décadas. Em uma noite agitada, a comitiva é visitada no hotel em que se hospedava por um grupo de jovens, muito jovens poetas e ensaístas locais, entre os quais Carlos Drummond de Andrade, Pedro Nava, Francisco Martins de Almeida e Emílio Moura.

Esse contato sem dúvida deixou grande impressão nos vanguardistas mineiros, mas a relação apenas se intensificaria alguns meses mais tarde, com o início de uma marcante troca epistolar que cada um deles travou com Mário de Andrade. O intuito deste artigo não é refazer a radiografia do movimento, aliás já muito bem estabelecida, ${ }^{\mathrm{I}}$ mas trabalhar uma determinada hipótese: a de que o modernismo não se restringiu exclusivamente a um campo profissional ou a um fazer artístico, mas tratou-se, antes, de um tipo específico de socialização, que implicou um movimento de formação intelectual e de formulação de uma visão de mundo. Desenvolvo essa hipótese em duas direções complementares, indicando como essa socialização procurava: I) construir um movimento coletivo - e, portanto, o modernismo deve aqui ser entendido en- 
quanto um movimento cultural; 2) modelar personalidades capazes de suportar os desafios impostos pelo tempo. Para isso me detenho em uma peça narrativa central dessa inteligibilidade, ainda praticamente ignorada pela crítica especializada: a correspondência de Pedro Nava com Mário de Andrade na década de i920, decisiva, como veremos, na modelagem do futuro autor das Memórias. ${ }^{2}$ De modo a calibrar essa leitura, também farei uso do que provavelmente é o mais importante corpus epistolar do modernismo, a correspondência entre Mário e Carlos Drummond de Andrade.

Em trabalhos recentes, a epistolografia de Mário de Andrade vem sendo entendida sociologicamente como peça fundamental da modelagem da subjetividade (Araujo, 20I4) e da sociabilidade (Botelho, 20I5) de toda uma geração. A partir dessa chave de leitura acredito ser possível perceber na troca de cartas - e também de versos, de críticas e de afetos - a conformação de uma espécie de teia coletiva que ia sendo tecida e que, no limite, implicava a abdicação da posse daquilo que era enviado, sedimentando, assim, um projeto modernista comum, coletivo, "nosso" - como se verá, por exemplo, na insistência de Mário de Andrade em utilizar a primeira pessoa do plural ao tratar das propostas de renovação do movimento. Como sugere André Botelho (201 2: 39-40), "o que não pode se perder de vista, fundamentalmente, é o reconhecimento [...] da parte de Mário de Andrade, de que a renovação cultural pela qual lutava envolvia o trabalho coletivo e a intensa interlocução inclusive entre gerações diferentes". As cartas seriam um meio privilegiado para essa interlocução.

Nesse sentido, cabe ressaltar ao menos duas dimensões implicadas na correspondência de Mário de Andrade, e que se configuram de maneiras específicas na relação com Pedro Nava. Primeiro, a personalidade e o método dialógico de Mário, como já estudado por Gilda de Mello e Souza (2009: 44) e que se configura enquanto um "discurso inacabado, na medida em que se abre continuamente para o interlocutor, exigindo a cada passo a sua participação efetiva no debate". Mário constituiria, assim, em sua "vocação para o diálogo", aquilo que a autora chama de um "temperamento socrático" (cf. Botelho \& Hoelz, 20I6). Silviano Santiago, também aproximando Mário da "maiêutica socrática", ressalta como o diálogo carrega uma alta carga de comprometimento não apenas individual, mas principalmente em nível societário, no sentido de que por meio dele e do consequente aperfeiçoamento dos homens também seria possível construir uma sociedade melhor. Nessa direção, Santiago sugere a centralidade do diálogo enquanto um gesto - radical - de alteridade, em que "puxar conversa" (a expressão é de Mário) é "um modo de se aproximar agressiva e despudoradamente, sensual e fraternalmente, do outro, para que o outro, ao passar de objeto a sujeito, transforme o sujeito que puxa conversa em objeto" (Santiago, 2006: I02).

Se pudermos levar a comparação com a figura de Sócrates adiante, notemos que não menos importante na correspondência entre Mário e Nava (as- 
sim como na de Drummond), e aqui entramos na segunda dimensão acima referida, é a presença constante de outra característica do diálogo socrático, mais especificamente aquilo que Michael Foucault resgatou sob o nome de "cuidado de si", entendido enquanto uma atitude ou um comportamento específico para consigo mesmo, mas também para com o mundo e com os outros. Como apontou em seu curso sobre a hermenêutica do sujeito, na Apologia de Sócrates este se apresenta como aquele que, fundamentalmente, "tem por função, ofício, encargo incitar os outros a se ocuparem consigo mesmos, a terem cuidados consigo e não descurarem de si" (Foucault, 2006: 7). O mestre, no caso, é aquele que "desperta", sendo o cuidado de si o momento do "primeiro despertar" do interlocutor, que passa primordialmente pelo exercício dialógico de uma nova forma de olhar.

É essencial, portanto, a qualidade do tipo de relação que se estabelece entre discípulos (sempre jovens) e mestre. Relação muitas vezes amorosa ou erótica, como fica claro em outro diálogo socrático, Alcebíades, e que normalmente implica o sacrifício do próprio mestre (Sócrates renuncia a sua fortuna, vantagens cívicas, à carreira política e, no limite, à própria vida). O cuidado de si, escreve Foucault (2006: I I), "é uma espécie de aguilhão que deve ser implantado na carne dos homens, cravado na sua existência, e constitui um princípio de agitação, um princípio de movimento, um princípio de permanente inquietude no curso da existência". Mário de Andrade, como veremos, será esse aguilhão. Por fim, é importante ressaltar que, consistente com a preocupação consigo mesmo, com uma dimensão pedagógica e com princípios de ação, o "cuidado de si", nota Foucault (I985: 59) em outra ocasião, longe de se situar na órbita do individualismo ou do egoísmo, implica antes a intensificação das relações sociais em um "jogo de trocas com o outro e de um sistema de obrigações recíprocas". Veremos, portanto, como Mário é importante na modelagem de uma geração, mas também na conformação de certos princípios de identidade e de personalidade.

\section{"A AVENTURA EM QUE ME METI"}

Entre a primeira vez que Mário e Nava se encontraram, na viagem dos modernistas a Minas Gerais, em I924, e a segunda, na capital paulista, em I933, passam-se sete anos. A distância, contudo, não implicou afastamento, como sabemos por sua troca de cartas. Ainda que bem menos volumosas do que a correspondência entre Mário e Drummond, essas 25 cartas (I 2 publicadas em Corres pondente contumaz e mais I 3 inéditas em livro, pertencentes ao acervo Mário de Andrade do Instituto de Estudos Brasileiros da USP) são igualmente reveladoras dos princípios de socialização que então se estabelecia.

Quando envia a primeira carta a Mário de Andrade - quase um telegrama, na concisão e na linguagem -, em I7/2/I925, Nava muito provavelmente já havia lido as três que o escritor paulista remetera a Drummond; afinal é notó- 
rio que suas cartas circulavam pelos jovens rapazes modernistas de Belo Horizonte. ${ }^{3}$ Nela, Nava acusa e agradece o recebimento de um livro, ${ }^{4}$ mas diz que o comentário da leitura iria mais tarde, atolado que estava com os exames da Faculdade de Medicina, de que então cursava o quarto ano. A brevidade não impede que, a exemplo da prática de seu colega, envie dois poemas, "Aterrissage" e "Reflexos":

Bello Horizonte, I7.2.1925

Meu caro Mário de Andrade.

Recebi seu livro.

Hoje quero só agradecer, deixando para conversar mais detalhadamente sobre elle, logo que houver tempo, isto é, depois dos meus exames na Faculdade de Medicina.

Mando pra Vce. ver e dizer o que pensa a respeito "Reflexos" e "Aterrissage". Um abraço do

Não deixa de chamar a atenção o caráter quase protocolar e pouco polido (além de nada reverencial) da mensagem com a qual o jovem de 2 I anos se aproximava de um dos líderes da Semana de Arte Moderna de São Paulo, para não falarmos do acento um pouco abusado, com o envio dos poemas sem nem antes um obrigado. Nada poderia ser, aliás, mais distante do que a primeira carta enviada por Drummond a Mário apenas alguns meses antes, em seu tom excessivamente formal e tímido, que se inicia da seguinte maneira:

Prezado Mário de Andrade,

Procure-me nas suas memórias de Belo Horizonte: um rapaz magro, que esteve consigo no Grande Hotel e que muito o estima. Ora, eu desejo prolongar aquela fugitiva hora de convívio com seu claro espírito. Para isso utilizo-me de um recurso indecente: mando-lhe um artigo meu que você lerá em dez minutos (Andrade \& Andrade, 2002: 40).

São, sem dúvida, duas maneiras absolutamente distintas para começar, incipitis que dizem muito não somente da personalidade de cada um, mas principalmente do tipo de relação que a partir dali iriam constituir com um interlocutor comum.

Mário de Andrade, respondendo a Nava em 9 de março, observa, como num puxão de orelhas, que, ao mandar uma primeira carta para alguém, o remetente deveria ao menos ter a gentileza de escrever o nome com mais clareza - algo que, afinal, não fazia tanta falta assim, uma vez que era ele o único que não havia confirmado o recebimento do livro. Sem saber, Nava dava em sua breve missiva o tom da correspondência com Mário de Andrade: a demora, o pedido de conselhos, a indicação de que os estudos de medicina estariam à frente da interlocução intelectual e mesmo a dificuldade em afirmar a própria identidade.

Logo na segunda carta, de 3/7/I925, Nava já parece realizar e ganhar consciência de seu autocentramento e de sua atitude pouco disciplinada para 
a escrita epistolar. Precisamente a "demora" será um dos grandes motes na correspondência, como se Nava preferisse resguardar certa distância de seu interlocutor, vendo-se constantemente tomado por afazeres que retardavam seguidamente as respostas. ${ }^{5}$

Meu caro Mário.

Já estou de orêlhas quentes. Decerto vcê. quando não tem nada que fazer e se põe de palestra com seus botões deve se regalar me tratando de canalha e outras suavidades no gênero. E tem razão. Carradas de razão. Sou. Vcê. me manda um livro seu e eu prá agradecer levo três mezes; como compensação martyriso vcê. com dois poemas tremendos - cynismo. Depois sua amabilidade me responde meia dúzia de linhas com meia dúzia de paginas; novamente eu espero outros três mezes e só então me decido a dar signal de que stou vivo - duplo cynismo. Só posso pedir é que vcê. me perdôe.

Parece ser precisamente a lógica do "pedido" - de conselhos, de análises, de livros ou mesmo de perdão - a que orienta a relação epistolar dos dois. Isso não impede, contudo, que, a exemplo do que ocorria com Drummond, Nava encare a correspondência com Mário enquanto um processo sobretudo educativo, de formação pessoal e intelectual. Na mesma carta, por exemplo, irá considerar os detalhados comentários de Mário como "bôas verdades e conselhos úteis, prá quem como eu stá se ensaiando", admitindo que, de fato, está tentando se corrigir. Remete, então, dois novos poemas, "Cantares da infância" e "Noite de São João", além de chamar atenção para uma resenha sobre o cubismo que escreveu no primeiro número de A Revista, que saía naqueles meses. Sobre A escrava que não é Isaura, notemos, nenhuma palavra novamente.

A correspondência parece ir se desenvolvendo sem rodeios. Nava não parecia buscar exatamente uma relação de intimidade, mas interessava-se, ao menos em um primeiro momento, naqueles "conselhos úteis" que lhe poderiam chegar pelo papel timbrado de um dos mais destacados críticos de sua geração. Mário, é claro, e com o perdão do duplo sentido, correspondia com sobras à expectativa. Suas duas primeiras cartas a Nava são, como já notaram alguns de seus intérpretes, primores da melhor crítica literária modernista (cf. Lafetá, 2004). Chama a atenção, por exemplo, para alguns vícios poéticos (9/3/I925), como a ênfase em aspectos técnicos e formais, que tenderiam a abafar as "sensações" líricas e, dessa maneira, se transformariam em fins em si mesmos, e não em meios que possibilitassem uma melhor expressão da "comoção" do poeta, isto é: "em vez de você se deixar levar pelo estado lírico [...] você se preocupou mais com o processo com que ia realizar o fato exterior em vez de observar o seu estado psicológico e por ele descrever o fato exterior" (Andrade, I982: 39; grifos nos original).

Na carta seguinte, de 2 I de julho do mesmo ano, outra é a lição de Mário, uma verdadeira aula sobre seu programa de "abrasileiramento da linguagem" e todas as dificuldades metodológicas implicadas na criação de uma "língua 
brasileira" (Andrade, I982: 53). De cara, elogia a "coragem de [Nava] entrar na luta", e tão cedo, lamentando que ele próprio só tenha feito isso muito tarde. Mas Mário insiste que as soluções para essa nova língua devem ser bem meditadas e, sobretudo, obedecer a princípios rígidos. Não se trata aqui de idiossincrasia nem propriamente de espontaneísmo, mas de uma "organização literária" (Andrade, I982: 54), que, por sua vez, não é somente popular ou regional, mas "geral que inclua todos os meios brasileiros burgueses e populares" (Andrade, I982: 54). Daí que Mário rejeitasse algumas das soluções encontradas por Nava em suas poesias, como a acentuação de todos os "pras" ("acentue só quando tiver contração com artigo") ou a grafia "star" em vez de "estar" ("star não é da índole tradicional da nossa língua doce e sensual um pouco lenta toda florida de vogais abundantíssimas").

A partir das cartas seguintes começamos a perceber que a ênfase de Mário de Andrade tende a incidir na importância do trabalho sistemático e do domínio das técnicas e das regras do "abrasileiramento" da linguagem. É assim, por exemplo, que Mário saúda o poema "Ventania", em I9/3/I926: “das milhores coisas que você tem me mandado. Além da boniteza real da poesia acho que você está empregando com um talento firme o abrasileiramento de sua expressão" (Andrade, I982: 65-66). ${ }^{6} \mathrm{O}$ elogio não vem sem aparos, mas sempre no mesmo sentido. No verso "O obelisco cortou ele pelo meio", o crítico sugere que Nava pense bem no uso do pronome pessoal, questionando se "esse processo é mesmo viável e organizável em norma, em generalização", afinal "não há língua minha conhecida onde o pronome sujeito sirva de complemento, sem estar flexionado" (Andrade, I982: 66). Como vemos, novamente fica claro que a experiência modernista, ao menos de corte marioandradiano, não implica incentivar uma escrita idiossincrática, mas sim capaz de obedecer a regras, padrões e, no limite, estabelecer um sistema coerente.

Podemos perceber nessas cartas um momento muito singular do próprio Mário de Andrade. Como anotou João Luiz Lafetá, entre Paulicéia desvairada (escrito em I920 e publicado em I922) e Clã do jabuti (I927) acentua-se a passagem da ênfase em um "fluxo do lirismo" e da obediência aos movimentos do subconsciente para um projeto de "socialização" do poema, como a "necessidade de pesquisar formas mais enraizadas na coletividade" que encarnariam o "ideal de uma língua literária brasileira" (Lafetá, 2004: 22 I-222). A aproximação programática da língua escrita com a falada no Brasil (Botelho, 20I2) é reincidente no diálogo com outros jovens correspondentes do mesmo período. Vejamos um longo fragmento de carta de I8/2/I925 a Carlos Drummond de Andrade em que Mário critica o uso excessivamente formal de determinadas preposições no poema "Nota social":

Veja bem, Drummond, que eu não digo pra você que se meta na aventura que me meti de estilizar o brasileiro vulgar. Mas refugir de certas modalidades nossas e perfeitamente humanas como o chegar na estação (aller en ville, arrivare in casa mia, 
andare in città) é preconceito muito pouco viril. [...] E já que falei na minha aventura peço uma coisa e aviso outra. Não pensem vocês, aí de Minas, que sou um qualquer leviano e estou dando por paus e por pedras sem saber bem o que estou fazendo. A aventura em que me meti é uma coisa séria já muito pensada e repensada. Não estou cultivando exotismos e curiosidades de linguajar caipira. Não. É possível que por enquanto eu erre muito e perca em firmeza e clareza e rapidez de expressão. Tudo isso é natural. Estou num país novo e na escureza completa duma noite. Não estou fazendo regionalismo. Trata-se duma estilização culta da linguagem popular da roça como da cidade, do passado e do presente. É uma trabalheira danada que tenho diante de mim. É possível que me perca mas que o fim é justo ou ao menos justificável e que é sério, vocês podem estar certos disso. Não estou pitorescando o meu estilo nem muito menos colecionando exemplos de estupidez. O povo não é estúpido quando diz "vou na escola", "me deixe", "carneirada", "mapear", "besta ruana", "farra”, "vagão", "futebol”. É antes inteligentíssimo nessa aparente ignorância porque sofrendo as influências da terra, do clima, das ligações e contatos com outras raças, das necessidades do momento e de adaptação, e da pronúncia, do caráter, da psicologia racial, modifica aos poucos uma língua que já não lhe serve de expressão porque não expressa ou sofre essas influências e a transformará afinal numa outra língua que se adapta a essas influências (Andrade \& Andrade, 2002: 100; grifos no original).

O modernismo entendido enquanto uma aventura, feita de erros e acertos. Notemos que Mário não pede exatamente que seus colegas (ele fala com Drummond no plural: "vocês, aí de Minas") embarquem nela como ele embarcara, e teremos a oportunidade de discutir mais adiante uma pista dessas razões, mas que entendam suas motivações e o brio da empreitada - e talvez com isso se convençam de sua necessidade. Mas o trecho não trata somente de questões estilísticas. Pelo contrário, como assinala o próprio Mário, o que está em jogo é inverter alguns sinais dos preconceitos culturais brasileiros, sobretudo a subserviência às gramáticas alheias (de Portugal, principalmente) e o desprezo da "linguagem popular", e com isso conferindo dignidade e valor aos próprios portadores dessa linguagem. Como resumiu Botelho (201 2: 74), "essa conquista modernista [aqui ainda em sua fase aventureira] não é uma conquista apenas estética, mas é também social e política, já que o reconhecimento da língua cotidiana e popular sem erudições implicou não só a renovação radical do código literário, como uma aproximação ao povo que deu voz própria ao homem brasileiro".

Como teria Nava assimilado essa lição aos mineiros? Em Io/4/I927 Mário acusa o recebimento de dois poemas, "Educação sentimental" (publicado em I927 na Revista do Brasil) e "Prelúdio número um" (publicado em I929 na Revista de Antropofagia). O primeiro, assinala, é "uma gostosura", o segundo "está bonitíssimo", mas lendo a carta vamos tendo a impressão de que pouco ali se salva. Dos versos "tinidos de pios e chilros pipocando pingos dos papos estufados", diz não entender a tendência em repetir a letra "p", "brincadeiras sem valor lírico nenhum e cujo valor artístico como onomatopeia é mais que duvidoso em muito sabido e muito fácil" (Andrade, I982: 87). Em "zumbaia de 
papagaios com as garras azedas de agarrarem uvaias ácidas", sugere a "retirada imediata do absolutamente inútil 'ácidas'", que além do mais "está positivamente prejudicando o ritmo do verso que sem esse apêndice fica muito mais ondulante" (Andrade, I982: 88). Finalmente, em "pranto deságua", repara na grafia "bem acentuad[a]": "Ora é desagúa que se fala e não deságua. Não venha me dizer que você não escreve portuga porém brasileiro e que fala assim. Não basta. Entre caboclos já escutei desagôa uma feita porém isso também não me basta para recomendar a forma. Não sei si é comum nem si é geral" (Andrade, I982: 89). Temos aqui novamente um pujante exemplo de como o abrasileiramente deveria ser organizado, uma "estilização culta da linguagem popular", nos termos da carta a Drummond anteriormente citada. Mário tinha a impressão de que alguns abrasileiramentos praticados por Nava eram criações excessivamente pessoais.

Se até agora nada parece se salvar, Mário finalmente faz algumas ressalvas, e não pouco importantes. Sobre os abusos na pessoalização, escreve que "falam a mesmíssima coisa de mim e sei que essa crítica que não faço porém sou tentado a fazer não tem importância real". Mais interessante, Mário faz o mais longo comentário sobre a curta "obra poética" de Pedro Nava:

E franqueza Nava: de todos os que se puseram a abrasileirar a própria fala palavra de honra que acho você o mais pessoal e interessante nesse ponto e o que se parece apenas consigo mesmo e não que esteja influenciado por alguém. E aliás a solução de você tem isso de valiosíssima que por mais que você empregue termos e modismos caboclos você conserva uma suntuosidade artística na dicção que é eminentemente literária e não oral. Ora, é justamente esse o que deve ser nosso propósito porque fala oral brasileira isso a gente já possui e não carece dela, a independência verdadeira está justamente em construir uma linguagem literária peculiarmente da gente, baseada na e distinta porém da fala oral (Andrade, 1982: 89-90).

A empreitada modernista estava apenas começando, e ninguém falou que seria fácil. Pelo contrário, a "aventura" era especialmente exigente "na escureza completa duma noite".

\section{"VOCÊ CARECE DE CONTINUAR SEMPRE"}

O caráter algo professoral de Mário de Andrade, aquele "gesto pedagógico" epistolar tão peculiar de que fala Marco Antonio de Moraes (2007: 5I), por uma vez pareceu querer sair das resmas de papel para ter lugar em um encontro de carne e osso. Talvez animado pelo entusiasmo com que os mineiros respondiam às suas cartas, Mário convida o grupo de Belo Horizonte para ir a São Paulo de férias. Essa espécie de "viagem de formação", que nunca ocorreu, atualizaria, ao revés, a "caravana" modernista. Enquanto esta foi descobrir o Brasil em Minas, Nava, Drummond e companhia eram instados a experimentar o mundo moderno em São Paulo. 
O convite se intensifica quando Mário descobre quase por acaso o que parecia ser um outro interesse artístico de Nava: o desenho. Para ilustrar os artigos que Drummond escreveria por ocasião do Mês Modernista no jornal A Noite, Nava desenhou um retrato do poeta que imediatamente chamou a atenção de Mário, que insiste na viagem a São Paulo, agora para que Nava pudesse ter acesso aos originais de quadros e desenhos, e não apenas a fotografias. Em todo caso, envia espontaneamente algumas fotos de quadros de Tarsila do Amaral, bem como se coloca à disposição para enviar livros de pintura.

A carta de resposta de Nava vem rápido, datada de I5/I/I926 e, surpreendentemente, longa. Nela, escreve mais detidamente sobre sua relação com a pintura e o desenho, suas dificuldades e intenções, algo que jamais fizera antes sobre a poesia. Ficamos sabendo, por exemplo, de um projeto para pintar uma famosa fotografia das prisioneiras de Canudos, assim como de sua fracassada tentativa de desenhar os soldados da mesma batalha. Também tomamos conhecimento das dificuldades que Nava encarava em seus estudos de desenhista: o vício em copiar o decadetismo do ilustrador inglês Aubrey Berdsley, corrigido com a ênfase em figuras obesas, anasarcadas; o mau uso das cores, excessivamente roxas e azuis, "resto de romantismo", que ia aos poucos substituindo por "bôas côres saborosas, nacionaes", "sem misturas nem meias tintas - rosa bem rosa, azul bem azul”. Na mesma carta, Nava se alonga pela primeira vez na crítica ao comentar as fotografias dos quadros de Tarsila, que valem adjetivos como "comoventíssimos", "genial", "enternecedor", mas que também sofrem algumas reprimendas, como na representação de certas árvores tropicais: "Uma pena, as palmeiras de 'Minas II': ferem demais os olhos já repousados pelos primeiros planos do quadro, tão redondos tão confortáveis e tão macios. Acho que Tarsila não descobrio ainda o coqueiro mas precisa fazêlo urgentemente".

A partir desse momento Nava passará a enviar a seu interlocutor tanto poemas quanto desenhos, que Mário seguirá comentando com empolgação. Já nos referimos à boa recepção do poema "Ventania". No entanto, seu grande entusiasmo parece ter se dado com o desenho Claudionor, que considerava, com outros enviados por Nava, "simplesmente delícias": "o mulato ['Claudionor']", diz Mário, "é simplesmente esplêndido. Milhor até que aquela poesia de você descrevendo aquela ventania em Belo Horizonte, coisa que você já sabe que acho estupenda. Continue a desenhar" (Andrade, I982: 80)7. A insistência tinha suas razões. Nava enviava seus trabalhos, mas o fazia em ritmo lento, pelo menos aquém das expectativas de Mário. As justificativas se seguiam e eram as mais variadas: "dor de corno" (22/3/I926), "obrigado a estudar muita medicina" (9/7/1926), "percauza dos ezames [da faculdade]", "meu mano [...] doente", "aborrecimento da gente aporrinhações dos sacanas que nos rodeiam a tristeza dos amigos que a gente sempre toma um pedaço" (as três últimas citações da carta de 7/4/1927, a mais longa da correspondência). No mesmo período ocorre ainda o fim de A Revista. 
Mário parecia reconhecer um problema em potencial, ou melhor, um problema no potencial. Se as expectativas eram as mais altas com os dotes que Nava ia apresentando para a arte moderna, antes na poesia e agora no desenho, também havia o risco grande daquilo tudo ficar pelo caminho. Essa preocupação, que não era apenas com Nava, mas com os jovens modernistas mineiros em geral, aparecerá principalmente nas cartas de 24/4/I 926 e 2I/I/I927, e por isso mesmo valerá a pena nelas nos deter um pouco.

A carta de abril de 1926 reage ao fim anunciado de A Revista, fato que irritou profundamente Mário. Um mês antes, em 22 de março, Nava havia chamado o terceiro número de o "canto de cisne" da publicação, fruto de um desânimo geral entre os editores pelas críticas que receberam em Belo Horizonte. A razão do desânimo é repudiada por Mário, que a considera "covarde e profundamente besta" (Andrade, I982: 74). Escrevendo em tom pouco comum na correspondência entre os dois (e repetido apenas na carta seguinte), e por isso mesmo bastante revelador das questões com que se defrontava o futuro autor de Macunaíma, pondera que esse desânimo seria resultado da percepção do esforço de renovação a ser feito, incansável e talvez mesmo impossível:

\footnotetext{
A gente se mete num movimento de renovação como o nosso, imagina logo e infantilmente que é só escrever uns versinhos e umas critiquinhas, pronto, tá tudo renovado, em vez a realidade chega e a gente põe reparo que não se renova assim à-toa que a base ruim é de pedra dura porque é o costume dos homens e sobretudo repara que tem um trabalho imenso em que terá de botar a vida inteira si quiser mesmo fazer alguminha coisa. E vai, se cansa de antemão e não tem coragem para começar de verdade o que terá de durar a vida toda. Essa é que é a causa verdadeira do desânimo de vocês (Andrade, I982: 74).
}

Mário já inclui Nava dentro do esforço coletivo - "nosso" -, esforço esse que tem de ser absoluto, quase ascético, se quiser dar o menor resultado. Renúncia, abdicação e, sobretudo, "sacrifício" são algumas das necessidades implicadas para a realização de um projeto, compreende-se melhor agora, comum. ${ }^{8}$ Outros já pereceram pelo caminho, faz questão de lembrar: "Os daqui [de São Paulo] quase todos desanimaram. Rubens [Borba de Moraes], Carlos Alberto de Araújo, Luís Aranha largaram de escrever e parece que pra sempre. Não aguentaram o repuxo. Foram frouxos como sempre chamo eles pra eles mesmos. Isso acho horrível" (Andrade, I982: 74-75). O julgamento grave sobre a fraqueza é sinal da insatisfação de Mário e, principalmente, da seriedade e da expectativa com a empreitada modernista, da qual exigia rigoroso comprometimento de todos os envolvidos.

Às declarações de desânimo e ao fim de A Revista talvez se somasse a impressão de que também Drummond parecia tomar um rumo pouco condizente com suas possibilidades criadoras. Cerca de um mês e meio antes da carta para Nava, em io de março, Mário escrevera outra em tom semelhante ao poeta, que acabara de mudar-se para Itabira. Nela vemos a inquietação com o 
abandono do trabalho intelectual e com o amolecimento do esforço crítico que já observamos no trato com Nava:

não quero absolutamente que você se perca aí e abandone as coisas de pensamento pra que tem um jeito certo e que fazem parte do destino de você, tenho a certeza. No que já reparei de você, me parece que você tem uma propensão danada pro desânimo e pro abatimento. Isolado dessa maneira você é capaz de se entregar pra terra e isso eu não quero (Andrade \& Andrade, 2002: 202).

Uma questão de destino trata-se, afinal, o temor de Mário, um destino que poderia não se realizar. Carlos confirma os temores, se diz "emburrecido" ("estou ficando burro. Sua carta já me encontrou emburrecido. Neste mês de março não li um só livro", p. 207), reclama da vida, se julga incapaz para a literatura e chega a ameaçar rasgar seu caderno de versos (lembremos que Drummond ainda não havia publicado um livro sequer nessa época). Não querendo correr o risco da ameaça, Mário solicita que Drummond envie para ele toda a sua produção poética. Ou melhor, exige, como se lê em carta de 8 de maio. É que os versos de Drummond deixavam de ser apenas dele: "Isso [rasgar o caderno] você não tem o direito de fazer e seria covardia. Você pode ficar pratiquísismo na vida se quiser porém não tem direito de rasgar o que não é mais só seu, que você mostrou pros amigos e eles gostaram" (Andrade \& Andrade, 2002: 215). É como se Mário observasse que junto à troca de cartas se fosse tecendo uma teia coletiva que implicava a abdicação da posse daquilo que era enviado. E justamente por ser coletivo, "nosso", o empenho deveria ser redobrado.

Voltando à carta para Pedro Nava de 24/4/I926, notamos que o tema do destino reaparece. Dessa vez, no entanto, Mário fala sobre si mesmo e sobre como sua atitude frente às dificuldades que o presente impunha era distante daquela observada em seus colegas mineiros e paulistas:

Não sei como é que isso pode se dar porque desânimo é sentimento que não sei como é. De repente sinto às vezes umas tinturinhas de cansaço no braço porém é coisa que passa logo, nem bem raia outro dia estou pensando em coisa nova. E note-se: si tem vida desanimadora é a minha porque meu ideal não é levar a vida que estou levando, meu ideal é uma vida especializada num ramo só de arte, digamos música como estudo e literatura como criação e só. Saber do resto só para enriquecimento lateral meu e não pra escrever sobre e no entanto escrevo sobre tudo, dou alarma de tudo porque si eu não der os outros não dão, faço crítica de tudo, faço versos faço jornalismo faço romance faço conto escrevo histórias musicais gramatiquinhas de língua, estéticas gerais, críticas literárias, tudo forçado pelas circunstâncias sem nada de profundo sem nada de bem pensado, pura vulgarização... É horrível Nava porque meu destino, destino não, meu ideal não era ser assim. E sou e não desanimo um momento. Alguma coisa há de ficar (Andrade, 1982: 75).

Detenhamo-nos um pouco nessa longa passagem. Mário utiliza a si mesmo como exemplo de atitude capaz de enfrentar os desafios poderosos impostos pelas demandas e exigências do tempo, o oposto daquela que linhas antes, 
na mesma carta, havia identificado em alguns de seus contemporâneos. O desânimo ou a frouxidão não teriam espaço no polígrafo incansável que mesmo nos momentos de dificuldade sabe que é necessário recomeçar a cada nascer do dia. Essa era, aliás, a única atitude adequada de modo a se preparar para levar a cabo um processo verdadeiro e profundo de renovação.

Por outro lado, o trecho também opera uma importante separação entre ideal e destino. Seu ideal, isto é, sua vontade, era a dedicação integral a uma especialidade artística, mas Mário parece se dar conta de que sua sina era outra, a de alguém que deveria jogar em todas as frentes. Estamos aqui diante da recursiva tópica do "sacrifício", central para a compreensão da obra e da trajetória de Mário de Andrade, como vem indicando a fortuna crítica do autor (cf. Fragelli, 20ıо; Botelho \& Hoelz, 20I6). Mas vejamos a pista: a justificativa que Mário oferece para a necessidade de estabelecer essa distinção entre ideal e destino, para o fato dele ter de fazer de tudo um pouco a despeito do que gostaria, essa única justificativa concerne ao fato de que "si eu não der [alarma de tudo] os outros não dão". Era necessário renunciar às próprias vontades, caso contrário ninguém faria aquilo que precisava ser feito. Mas se sacrificar pelo quê? O que haveria de ficar? Certamente não sua própria obra, que afinal ele mesmo tratava de "pura vulgarização", mas, diz na mesma carta, "alguma coisa mais importante que a minha possível importância futura tenho certeza que ficará e em que tive minha importância: a vida de todos pela qual não sei porque mistério imenso a gente se sacrifica amando sem querer" (Andrade, I 982: 75-76). O sentido do autossacrifício de Mário de Andrade passa, portanto, não apenas por uma modificação de si, mas também do outro.

Vejamos rapidamente outro corpus epistolar de um contemporâneo de Nava e Drummond que pode nos auxiliar. Cerca de seis meses antes da carta que estamos trabalhando, em 3/ıo/ı925, Mário escreve a Prudente de Morais, neto (I985: 99), uma missiva de teor muito semelhante. Não poderemos nos deter nos vários assuntos tratados, mas já no final Mário comenta a respeito de um artigo que seu interlocutor havia publicado na revista Estética sobre A escrava que não é Isaura, considerando-o "o milhor que a Escrava despertou até agora". Dentre as discordâncias, porém, ressalta uma: a "necessidade de comunicação". Em sua longa resenha, Prudente reproduzira a fórmula de Mário sobre os elementos produtores das belas artes ("Necessidade de expressão + necessidade de comunicação + necessidade de ação + necessidade de prazer = Belas Artes"), concordando com sua conclusão mais geral sobre "mostrar que o montão de enfeites que Rimbaud chutou para longe da poesia só servia mesmo para atrapalhar" (Morais, neto, I985: I3I). O criador de Estética, no entanto, fazia a ressalva de que, aceitando a conclusão, modificaria os fatores da fórmula e "suprimia a necessidade de comunicação, que pra mim não é elemento indis pensável" (Morais, neto, I985: I3I). Prudente de Morais, neto, desenvolve uma verdadeira teoria sobre o assunto, que não seria o caso de reproduzir aqui. 
Interessa-nos, contudo, a resposta, algo insegura, de Mário de Andrade. A passagem é novamente longa, mas vale a pena:

Você é muito moço. Eu também na sua idade não vê que aceitava isso [a necessidade de comunicação]! E não estou convencido que estou com a razão. Acho que desta vez incorro numa observação finíssima e muito certa que o Drummond fez sobre mim quando eu falei na redescoberta da eloquência, na Escrava. Ele disse que eu meio que estava numa defesa pro domo. Minha vida de homem (incluo o artista desde Pauliceia neste homem) tem sido um constante sacrifício de mim mesmo pelos outros. Não falo isso pra que me admirem nem me agradeçam: questão de temperamento [...] Minha arte nem é bem arte porque vive arreada dum mundo de preocupações interessadas não pra mim o que seria justificável porém pros outros. Não faço arte, ensino. Pode ser que ensine mal porém a intenção é de ensinar bem. Só em Pauliceia fiz arte desarreada de intenções. Todo o resto até agora e creio que até o fim por mais aparência de arte que tenha tem pra mim destino diferente do de arte. Talvez por isso eu ache imprescindível a necessidade de comunicação. Acho (Morais, neto, I985: I22).

Mário de Andrade aproxima aqui duas categorias fundamentais: sacrifício e comunicação. Já vimos que são esses os elementos fundamentais de sua "postura socrática", e temo-los agora juntos, como se sacrifício e comunicação não se distinguissem. Ou melhor, o ato de sacrificar-se, ao ser pelos outros, é em si mesmo um efeito de comunicação: sacrificar-se é comunicar. A correspondência de Mário é como que encantada porque quem a recebe na verdade está recebendo algo desse espólio sacrificial, Mário está se sacrificando por seus interlocutores, não à toa seus discípulos. Há uma gota de sangue em cada carta.

Por aí vemos a gravidade implicada na comunicação epistolar de Mário de Andrade. Não se tratava de modo algum de partilhar "conselhos úteis", como solicitava um ainda ingênuo Pedro Nava, mas de estabelecer a possibilidade de um destino. Possibilidade porque Mário antevia que a única maneira daqueles jovens - Nava, Drummond, Martins de Almeida, Prudente de Morais, neto, Sérgio Buarque de Holanda e tantos outros - se realizarem seria na anulação de sua própria pretensão por uma "obra acabada". Cumprir o seu destino seria abrir as condições de possibilidade para outros destinos.

Dádivas, já ensinou Marcel Mauss (2003: 232), são simultaneamente interessadas e desinteressadas, e no seu cerne está a possibilidade de estabelecer comunhões e alianças. Mesmo que pressupondo sacrifícios, uma de suas lições, assim lemos na bela (e socrática) conclusão do famoso ensaio, fala de como o bem e a felicidade podem ser encontrados no "respeito mútuo e na generosidade recíproca" (Mauss, 2003: 3I4). Se Mário de Andrade se sacrifica, isso por si mesmo não basta. Ricardo Benzaquen de Araújo (20I4: I84) já ressaltou, na chave maussiana que inspira essa leitura, como há algo de paradoxal na troca de cartas: ela é ao mesmo tempo um meio privilegiado para a ampliação dos vínculos de amizade e extremamente precária, porque sempre incerta, e nessa incerteza há constantemente a possibilidade da fissura e da "mais completa 
e por vezes inesperada dissidência". As cartas caminham a todo o tempo nessa tênue linha entre sacrifício, reciprocidade e dissidência.

Já vimos a preocupação de Mário com o esmorecimento de Drummond e Nava, quando por um fio esse trançado poderia ter sido desfeito. Ela novamente se repete em carta do dia 2I/I/I927. Nela, Mário escreve duas vezes logo nas primeiras linhas, como numa espécie de motto, a frase "você carece de continuar sempre” (Andrade, I982: 79). Logo sabemos, no entanto, que não se trata de uma indicação pontual, mas sim generalizada. Vejamos um trecho:

O que falta para você e em geral para vocês (menos pelo que eu estou vendo no Diário de Minas, pro João Alphonsus, vida bonita) é entusiasmo permanente. [...] Falta para vocês organizarem a vida da sensibilidade criadora numa corrente contínua que pode e terá naturalmente seus momentos de excesso de força (os momentos grandes) porém não cessa nunca. Que nem eu, este diabo de bobão que está na frente de você. É uma pena que vocês não sejam assim [...]. Que você é poeta outras coisas provam também. Agora o que carece é alimentar a sacra chama, excusez! Porém por causa do muito que estamos matutando e este diabo de temperamento crítico, excessivamentissimamente crítico que a nossa época nos deu ponha reparo no poder de falhados que estão aparecendo no modernismo. De vez em quando uma mijadinha de arte e depois passamos anos e às vezes a vida inteira sem mijar mais. Uma porrada de rimbaudzinhos infelizes e ridículos afinal, si não fosse tão doloroso. Eu não queria que você fosse desses... (Andrade, 1982: 79-80).

Mário de Andrade sabia muito bem que o sucesso de um projeto como o modernista, pelo qual ele se sacrificava, não podia se valer de espasmos geniais ou de poetas precoces, mas apenas de um esforço continuado, sistemático, permanente. Não necessitava de diletantes, mas de uma atitude que quase poderíamos chamar de profissional: a poesia, a pintura, a prosa, a crítica, cada uma dessas especialidades deveria ser praticada antes com o esmero de um funcionário do que com as idiossincrasias de um enfant terrible. Nesse sentido, critica a preguiça, o desleixo e a falta de cuidado para com as empreitadas artísticas: ${ }^{9}$

Olhe Pedro Nava não tem nada como a gente se respeitar a si mesmo. Isso não é vaidade, é dever. Homem, já estou pensando agora que o carvão não se espalha [no papel] porque você colore em seguida com aquarela. Continue no seu processo e tendências, mas aperfeiçoando a técnica desses processos assim como estou falando e garanto que você fará coisas magistrais [...] Sucedeu que se fatigaram por demais e não aguentaram o tranco, estão bancando os rimbaudzinhos. Não faça assim, faz favor, trabalhe e trabalhe sempre (Andrade, I982: 8I).

É interessante notar que Mário, em vários momentos da correspondência, mais claramente nos de desânimo do interlocutor, parece enfatizar a necessidade da modelagem de um tipo específico de "personalidade", entendida aqui heuristicamente com o auxílio do tipo ideal weberiano, isto é, enquanto uma relação constante com certos "valores últimos" convertidos em objetivos de vida (Weber, 2012: 85-92), ou ainda como a "entrega a uma causa" (Schluchter et al., 
I990: 249). A personalidade vista nesses termos exige uma forte carga de disciplina, um tipo de "adestramento" que se "propõe a habilidade mecanizada por meio do 'treino' e, desde que apele a fortes motivos de caráter 'ético', a orientação no 'dever' e na 'consciência'” (Weber, I 999: 357). O que a disciplina procura conformar é uma personalidade intensa, rígida, que não conheça o esmorecimento, uma "vigilância continuada", na justa expressão de Helena Bomeny (I994: I83). ${ }^{\text {Io }}$ Exatamente essa se torna a preocupação da correspondência de Mário com Nava, sobretudo nas últimas cartas trocadas nos anos I920, antes de um longo hiato epistolar, só retomado em I943. Como vimos, Mário opõe os "frouxos" e o "desânimo" a uma retórica extremamente forte e viril - "entusiasmo permanente", "corrente contínua", "sacra chama". A única maneira de garantir o cumprimento de seu destino sacrificial seria assegurando que seus jovens interlocutores mantivessem a orientação de suas condutas sempre alertas.

Se há algo que caracteriza a amizade entre Nava e Mário nos anos 1920 é sem dúvida a exigência, uma forte impressão de que por trás da troca de cartas há certos deveres, "deveres de virtude com os outros", para falar como Kant (2003), que conformam uma determinada ética não apenas epistolar, mas de conduta; não somente individual, mas coletiva. Não parece aleatório o fato de que, uma vez perceptível a ideia de que Pedro Nava não se dedicaria a "continuar sempre", as cartas sejam interrompidas e a amizade entre ambos continue, mas precise se reconfigurar em novos termos. ${ }^{\text {II }} \mathrm{O}$ mesmo não ocorre com seu colega de Café Estrela, Carlos Drummond de Andrade, cuja larga correspondência com Mário, apesar dos diferentes matizes observados ao longo do tempo (Andrade, 20I5; Botelho, 20I5; Santiago, 2002;), se conservou razoavelmente constante, acompanhando tanto as modificações da vida e da literatura de cada um quanto as do contexto político e social brasileiro.

Aquelas cartas que começavam de modos tão diferentes em meados dos anos I920 chegavam ao final da década demarcando três destinos cruzados, mas também distintos. As questões que atravessavam a divisa entre Minas Gerais e São Paulo eram muitas vezes as mesmas, mas foram elaboradas por nossos personagens à maneira de cada um; afinal as relações que se estabeleciam entre eles eram necessariamente únicas, bem como as personalidades modeladas. É interessante como Mário de Andrade ao mesmo tempo em que percebia o modernismo muito além de sua dimensão artística e enquanto um amplo movimento de renovação cultural capaz de "tornar o Brasil familiar aos brasileiros" (Botelho, 20I 2: 77), estava forjando seus portadores e colegas de aventura dentro de rigores quase especialistas. Como se visse em Nava e Drummond a possibilidade de realização de uma obra que ele próprio teve de sacrificar para cumprir aquilo que considerava ser seu destino, conforme discutimos. 
PERSONALIDADE E DESTINO: PEDRO NAVA, MÁRIO DE ANDRADE E A SOCIALIZAÇÃO DO MODERNISMO

250

Andre Bittencourt é mestre e doutor em sociologia pelo Programa de Pós-Graduação em Sociologia e Antropologia da UFRJ. É pesquisador de Pós-Doutorado (PDJ/CNPq) na Casa de Oswaldo Cruz (COC-Fiocruz) e integrante do Núcleo de Estudos Comparados e Pensamento Social - NEPS (UFRJ/UFF) e da Biblioteca Virtual do Pensamento Social - BVPS. É autor do livro O Brasil e suas diferenças: uma leitura genética de Populações Meridionais do Brasil (2013). 


\section{NOTAS}

I Talvez seja possível dizer, sem exagero, que o modernismo mineiro é, de todos os modernismos do início do século XX no Brasil, aquele com a fortuna crítica mais coerente em seus elementos principais. Para abordagens sistemáticas remeto o leitor aos trabalhos fundamentais de Dias (I97I); Bueno (I982); Werneck (I992); Bomeny (I994); Marques (20II).

2 A partir de 1972 Pedro Nava inicia, com o livro Baú de ossos, a publicação de sua obra memorialística, muitas vezes considerada um "fruto tardio" do modernismo e que, aliás, teria impacto importante nas releituras do próprio movimento (cf. Arrigucci Júnior, 1987; Candido, 1989; Cançado, 2003; Valle Neto, 20II; Botelho, 2013).

3 Em "Evocação da rua da Bahia" Pedro Nava (20I2: 4I4-4I5) descreve dessa maneira os encontros dos jovens rapazes no Café Estrela de Belo Horizonte: "E conversávamos perdidamente... Sobre as cartas do Mário, sobre o manifesto do 'pau-brasil', sobre os rapazes de Cataguases, sobre o aparecimento da Estética, sobre o lançamento da Revista, sobre a recuperação das amadas e a poesia do mundo".

4 Pela resposta de Mário de Andrade sabemos tratar-se de A escrava que não é Isaura. Mário enviara alguns exemplares do livro a Carlos Drummond de Andrade quase um mês antes, solicitando que este divulgasse a obra em Belo Horizonte. Cf. a carta de Mário de Andrade a Carlos Drummond de Andrade de 2I/I/I925.

5 Para uma análise das cartas como forma de manutenção da distância, cf. Kaufmann (I990).

6 Mário de Andrade indica que citou o poema quase por inteiro em um artigo sobre "Tendências da poesia brasileira contemporânea". Em nota, o organizador do livro Correspondente contumaz, Fernando da Rocha Peres, diz não haver encontrado esse artigo de Mário de Andrade, que teria sido preparado para a revista Mocidade, de São Paulo (cf. Andrade, I982: 69, nota 42). Tampouco consegui localizar a publicação. O poema é dedicado ao próprio Mário.

7 Segundo Fernando da Rocha Peres foram cinco os desenhos enviados por Nava a Mário de Andrade ao longo de toda a correspondência: “I) 'Claudionor' (único com nome); 2) figura sentada; 3) dois nus femininos; 4) a jogadora de tênis" (Andrade, I982: 84, nota 59, grifo no original). 
8 Convém ressaltar que falar em um "projeto modernista" ou de um "sistema" de organização da linguagem não implica necessariamente o reconhecimento de algo como uma "identidade nacional" estável, e muito menos de qualquer dimensão "ontológica". Sobre esse assunto, cf. Botelho (2013); Hoelz (2015).

9 Lembremos que a dedicatória de Macunaíma que Mário escreve a Nava é: "A / Pedro Nava, / pouco trabalhador, / pouco trabalhador". Nava devolve o exemplar com oito guaches desenhados.

Io Em A ética protestante e o espírito do capitalismo Weber trata o protestantismo precisamente como uma das mais poderosas formas de personalidade desenvolvidas no Ocidente, sobretudo por meio da ascese intramundana (Weber, 2004: I08-I09). Foi essa personalidade metódica que, segundo ele, permitiu aos protestantes seu "enorme poder de triunfar do mundo" (Weber, 2004: I09). Para a discussão sobre o conceito de personalidade, cf. Brubaker (I984); Goldman (I988, I992) e Schroeder (I99I). Para uma crítica recente à abordagem "orientalista" de Weber em seus estudos sobre a personalidade, cf. Farris (2013).

I I Sobre a importância de Mário de Andrade para a compreensão de Pedro Nava sobre medicina, cf. Bittencourt \& Botelho (20I5); Bittencourt (2017, especialmente cap. 3).

\section{REFERÊNCIAS BIBLIOGRÁFICAS}

Andrade, Carlos Drummond de. (2015). Apresentação. In: Andrade, Mário. A lição do amigo. São Paulo: Companhia das Letras.

Andrade, Mário de. (1982). Correspondente contumaz. Cartas a Pedro Nava (I925-1944). Rio de Janeiro: Nova Fronteira.

Andrade, Mário de \& Andrade, Carlos Drummond de. (2002). Carlos \& Mário (org. de Santiago, Silviano). Rio de Janeiro: Editora Bem-Te-Vi.

Araújo, Ricardo Benzaquen de. (20I4). Um grão de sal: autenticidade, felicidade e relações de amizade na correspondência de Mário de Andrade com Carlos Drummond. História da Historiografia, Ouro Preto, I6, p. I74-I85. 
Arrigucci Júnior, Davi. (1987). Enigma e comentário: Ensaios sobre literatura e experiência. São Paulo: Companhia das Letras.

Bittencourt, Andre. (2017). A incisão e a lira: medicina, literatura e modernismo em Pedro Nava. Tese de doutorado. PPGSA/Universidade Federal do Rio de Janeiro.

Bittencourt, Andre \& Botelho, André. (2015). Entre bruxos e doutores: medicina e modernismo em Pedro Nava. Novos Estudos Cebrap, São Paulo, I02, p. I7I-I89.

Bomeny, Helena. (I994). Guardiães da razão: modernistas mineiros. Rio de Janeiro: Ed. UFRJ/Edições Tempo Brasileiro.

Botelho, André. (2015). Posfácio. In: Andrade, Mário. A lição do amigo. Cartas de Mário de Andrade a Carlos Drummond de Andrade. São Paulo: Companhia das Letras.

Botelho, André. (2013) O modernismo barroco de Pedro Nava. In: Nava, Pedro. Beira-mar. São Paulo: Companhia das Letras.

Botelho, André. (2012). De olho em Mário de Andrade: uma descoberta intelectual e sentimental do Brasil. São Paulo: Claroenigma.

Botelho, André. \& Hoelz, Maurício. (2016). O mundo é um moinho: sacrifício e cotidiano em Mário de Andrade. Lua Nova, São Paulo, 97, p. 25I-284.

Brubaker, Roger. (1984). The limits of rationality: an essay on the social and moral thought of Max Weber. London/Boston: Allen \& Unwin.

Bueno, Antonio Sérgio. (I982). O modernismo em Belo Horizonte: década de vinte. Belo Horizonte: Ed. UFMG.

Cançado, José Maria. (2003). Memórias videntes do Brasil. A obra de Pedro Nava. Belo Horizonte: Ed. UFMG.

Candido, Antonio. (1989) Poesia e ficção na autobiografia. In: Candido, Antonio. A educação pela noite e outros ensaios. São Paulo: Ática.

Dias, Fernando Correia. (I97I). O movimento modernista em Minas, uma interpretação sociológica. Brasília: Embrasa.

Farris, Sara. (2013). Max Weber's theory of personality: individuation, politics and orientalism in the sociology of religion. Leiden: Brill. 
Foucault, Michel. (2006). A hermenêutica do sujeito: curso dado no Collège de France, I98I-I982. São Paulo: Martins Fontes.

Foucault, Michel. (1985). História da sexualidade III: o cuidado de si. Rio de Janeiro: Edições Graal.

Fragelli, Pedro. (2010). A paixão segundo Mário de Andrade. Dissertação de Mestrado. FFLCH/Universidade de São Paulo.

Goldman, Harvey. (1992). Politics, death, and the devil: self and power in Max Weber and Thomas Mann. Berkeley: University of California Press.

Goldman, Harvey. (1988). Max Weber and Thomas Mann: calling and the shaping of the self. Berkeley: University of California Press.

Hoelz, Maurício. (20I5). Entre piano e ganzá: música e interpretação do Brasil em Mário de Andrade. Tese de Doutorado. PPGSA/Universidade Federal do Rio de Janeiro.

Kant, Immanuel. (2003). A metafísica dos costumes. São Paulo: Edipro.

Kaufmann, Vincent. (I990). L'équivoque épistolaire. Paris: Les Éditions de Minuit.

Lafetá, João Luís. (2004). A dimensão da noite. São Paulo: Duas Cidades/Ed. 34.

Marques, Ivan. (20II). Cenas de um modernismo de província: Drummond e outros rapazes de Belo Horizonte. São Paulo: Ed. 34 .

Mauss, Marcel. (2003). Ensaio sobre a dádiva. In: Mauss, Marcel. Sociologia e antropologia. São Paulo: Cosac \& Naify. Mello e Souza, Gilda de. (2009). Exercícios de leitura. São Paulo: Duas Cidades/Ed. 34.

Moraes, Marcos Antonio. (2007). Orgulho de jamais aconselhar: a epistolografia de Mario de Andrade. São Paulo: Edusp. Nava, Pedro. (2012). Chão de ferro. São Paulo: Companhia das Letras.

Morais Neto, Prudente de. (1985). A escrava que não é Isaura [Resenha]. In: Koifman, Georgina. Cartas de Mario de Andrade a Prudente de Moraes, neto (1924/36). Rio de Janeiro: Nova Fronteira. 
Santiago, Silviano. (2006). Ora (direis) puxar conversa! Belo Horizonte: Ed. UFMG.

Santiago, Silviano. (2002). Suas cartas, nossas cartas. In: Andrade, Mário de \& Andrade, Carlos Drummond de. Carlos \& Mário (org. de Santiago, Silviano). Rio de Janeiro: Editora Bem-Te-Vi.

Schluchter, Wolfgang et al. (I990). Max Weber e o projeto da modernidade. Lua Nova, São Paulo, 22, p. 229-257.

Schroeder, Ralph. (I99I). "Personality" and "inner distance": the conception of the individual in Max Weber's sociology. History of the Human Sciences, 4/I, p. 6I-78.

Valle Neto, Júlio de Souza. (20I I). O modernista no antiquário: Pedro Nava, as memórias e o modernismo. Tese de Doutorado. Universidade Estadual de Campinas.

Weber, Max. (2012). Roscher and Knies and the logical problems of historical economics. In: Bruun, Hans \& Whimster, Sam. (ed.). Max Weber collected methodological writings. London/New York: Routledge.

Weber, Max. (2004). A ética protestante e o espírito do capitalismo. São Paulo: Companhia das Letras.

Weber, Max. (I999). Economia e sociedade: fundamentos da sociologia compreensiva. Brasília: Ed. UNB.

Werneck, Humberto. (1992). O desatino da rapaziada: jornalistas e escritores em Minas Gerais. São Paulo: Companhia das Letras.

\section{Correspondência não publicada}

Correspondência passiva de Mário de Andrade com Pedro Nava. Acervo Mário de Andrade (IEB). Caixa 236. 
PERSONALIDADE E DESTINO: PEDRO NAVA, MÁRIO DE ANDRADE E A SOCIALIZAÇÃO DO MODERNISMO Resumo

O objetivo do artigo é discutir a hipótese de que o modernismo dos anos 1920 pode ser pensado sociologicamente como um tipo de específico de socialização. Com o intuito de trabalhar essa questão, mobiliza-se a correspondência ainda pouco explorada de Pedro Nava com Mário de Andrade, assim como uma parcela das cartas deste último com Carlos Drummond de Andrade trocadas naquela década. Além das questões mais exploradas pela crítica, como a importância de temas como o "abrasileiramento da linguagem", procura-se demonstrar como essas peças narrativas implicam simultaneamente a conscientização de um projeto coletivo e a modelagem de um tipo específico de "personalidade" capaz de enfrentar os desafios impostos pelas exigências de um processo profundo de renovação que então se propunha.

\section{PERSONALITY AND DESTINY: PEDRO NAVA, MÁRIO DE ANDRADE AND THE SOCIALIZATION OF MODERNISM} datter with Carlos Drummond de Andrade during the same critical literature, such as the importance of themes like the 'Brazilianization of language,' I aim to show how these narrative elements simultaneously imply awareness of a collective project and the shaping of a specific kind of 'personality' capable of confronting the challenges imposed by the demands of the deep process of renewal proposed during this period.
Palavras-chave

Modernismo;

Pedro Nava;

Mário de Andrade; pensamento social brasileiro; amizade.

\section{Keywords}

Avant-garde;

Pedro Nava;

Mário de Andrade; Brazilian social thought; friendship. 